\title{
Article \\ Electrospinning Preparation of GaN:ZnO Solid Solution Nanorods with Visible-Light-Driven Photocatalytic Activity toward $\mathrm{H}_{2}$ Production
}

\author{
Jingyun Mao ${ }^{1,2} \mathbb{D}$, Huiling Zhong ${ }^{1,2}$, Xinpin Liu ${ }^{1,2}$, Qingrong Qian ${ }^{1,2} \mathbb{D}$, Yongjin Luo ${ }^{1,2}$, Liren Xiao ${ }^{1,2, *}$ \\ and Hun Xue $1,2, *$
}

\section{check for}

updates

Citation: Mao, J.; Zhong, H.; Liu, X.; Qian, Q.; Luo, Y.; Xiao, L.; Xue, H.

Electrospinning Preparation of GaN:ZnO Solid Solution Nanorods with Visible-Light-Driven

Photocatalytic Activity toward $\mathrm{H}_{2}$ Production. Appl. Sci. 2021, 11, 10854. https://doi.org/10.3390/ app112210854

Academic Editors: Jun-Jun Xiao, Qiang Zhang and Zhenzhen Liu

Received: 7 October 2021

Accepted: 8 November 2021

Published: 17 November 2021

Publisher's Note: MDPI stays neutral with regard to jurisdictional claims in published maps and institutional affiliations.

Copyright: (c) 2021 by the authors. Licensee MDPI, Basel, Switzerland. This article is an open access article distributed under the terms and conditions of the Creative Commons Attribution (CC BY) license (https:/ / creativecommons.org/licenses/by/ $4.0 /)$.
1 College of Environmental Science and Engineering, Fujian Normal University, Fuzhou 350007, China; mjy19960427@163.com (J.M.); zhongh11998@163.com (H.Z.); lxpwkm@fjnu.edu.cn (X.L.); qrqian@fjnu.edu.cn (Q.Q.); yongjinluo@fjnu.edu.cn (Y.L.)

2 Fujian Key Laboratory of Pollution Control \& Resource Reuse, Fujian Normal University, Fuzhou 350007, China

* Correspondence: xlr1966@fjnu.edu.cn (L.X.); xuehun@fjnu.edu.cn (H.X.)

\begin{abstract}
The development of a facile method for the synthesis of GaN: $\mathrm{ZnO}$ solid solution, an attractive material with a wurtzite-type structure, is vital to enhance its photocatalytic activity toward $\mathrm{H}_{2}$ evolution. Herein, $\mathrm{GaN}: \mathrm{ZnO}$ solid solution nanorods with diameters of around $180 \mathrm{~nm}$ were fabricated by combining the electro-spun method with a sequentially calcinating process. Photocatalytic water-splitting activities of the as-obtained samples loaded with $\mathrm{Rh}_{2-y} \mathrm{Cr}_{\mathrm{y}} \mathrm{O}_{3}$ co-catalyst were estimated by $\mathrm{H}_{2}$ evolution under visible-light irradiation. The as-prepared $\mathrm{GaN}: \mathrm{ZnO}$ nanorods at a nitridation temperature of $850{ }^{\circ} \mathrm{C}$ showed the optimal performance. Careful characterization of the GaN: $\mathrm{ZnO}$ solid solution nanorods indicated that the nitridation temperature is an important parameter affecting the photocatalytic performance, which is related to the specific surface area and the absorbable visible-light wavelength range. Finally, the mechanism of the GaN:ZnO solid solution nanorods was also investigated. The proposed synthesis strategy paves a new way to realize excellent activity and recyclability of $\mathrm{GaN}: \mathrm{ZnO}$ solid solution nanorod photocatalysts for hydrogen generation.
\end{abstract}

Keywords: GaN:ZnO solid solution nanorods; electrospinning technology; hydrogen evolution; visible-light photocatalysis

\section{Introduction}

In recent years, the modern energy crisis has been one of the major problems that has concerned human beings in the 21st century. Therefore, a recent flourish of studies have been inspired to develop environmental-friendly and renewable fuels [1]. Particularly, the use of photocatalytic water splitting for hydrogen production is an attractive strategy in the field of energy conversion with abundant solar energy, since the pioneering report of photoelectrochemical water splitting was published in 1972 [2]. Currently, a lot of photocatalysts, such as $\mathrm{TiO}_{2}$ [3-5], $\mathrm{WO}_{3}$ [6,7], g- $\mathrm{C}_{3} \mathrm{~N}_{4}$ [8-10], $\mathrm{ZnO}$ [11-13], and metal complexes [14-16], have been employed for the photocatalytic water splitting reaction. However, it has been demonstrated that most of these photocatalysts with wide band gaps are only active under UV irradiation. Thus, it is vital to develop a highly active photocatalyst with a sufficiently narrower bandgap for efficient visible-light-driven hydrogen production.

So far, nitride $[17,18]$ or metal oxynitrides $[19,20]$, absorbing visible light with a larger wavelength range, have been found to be capable of splitting water into hydrogen and oxygen under visible-light illumination. Among them, GaN:ZnO solid solution possesses a wurtzite-type structure with a $\mathrm{d}^{10}$ typical electronic configuration, which has been actively investigated [21,22]. It shows a narrower band gap, ranging from $2.4 \sim 2.8 \mathrm{eV}[23,24]$, which can be ascribed to the p-d repulsion in the valence band between Ga3d/Zn3d and $\mathrm{N} 2 \mathrm{p} / \mathrm{O} 2 \mathrm{p}$ [25]. However, as for GaN:ZnO solid solution, due to the lack of $\mathrm{H}_{2}$ evolution 
sites, it is necessary to employ a cocatalyst that plays a vital role in providing active sites and improving the charge separation for photocatalytic redox reactions [26-28]. $\mathrm{Rh}_{2-y} \mathrm{Cr}_{\mathrm{y}} \mathrm{O}_{3}$, as a traditional cocatalyst, has been found to be capable of promoting the realization of the photocatalytic water splitting $[29,30]$. Therefore, high-efficiency GaN:ZnO solid solutions decorated with cocatalyst of $\mathrm{Rh}_{2-y} \mathrm{Cr}_{\mathrm{y}} \mathrm{O}_{3}$ were designed and prepared.

Typically, GaN:ZnO is synthesized by nitriding the mixture of $\mathrm{Ga}_{2} \mathrm{O}_{3}$ and $\mathrm{ZnO}$ under anhydrous $\mathrm{NH}_{3}$ gas flow, and calcinating it for a relatively long reaction period to guarantee a successful formation of solid solution [21,31,32]. However, the as-prepared $\mathrm{GaN}: \mathrm{ZnO}$ possesses a non-uniform elemental distribution of $\mathrm{Zn}$ and $\mathrm{Ga}$ after long-term nitriding [24,33]. Herein, it is significant to develop a facile and versatile approach to prepare the GaN:ZnO solid solution with higher homogeneous particles. In recent years, electrospinning has been proven as a simple and widely used technology for the preparation of nanofiber materials with a larger specific surface area and better light harvesting ability [34-36]. The electro-spun nanofibers also show good recoverable character in comparison to nano-powders [37]. Furthermore, the problem of the elemental aggregation of $\mathrm{GaN}$ :ZnO solid solution can be efficiently eliminated by immobilizing the elements of Ga and $\mathrm{Zn}$ on polyacrylonitrile (PAN) during the electro-spun process [38].

In this study, we present for the first time nanorod $\mathrm{GaN}: \mathrm{ZnO}$ solid solutions prepared using an electrospinning method for photocatalytic $\mathrm{H}_{2}$ production under visible-light irradiation. The phase microstructure and morphology of the nanorods prepared at different nitriding temperatures were determined. The optical properties were evaluated via UV-vis diffuse reflectance spectra (DRS), photoluminescence (PL), and an electrochemistry workstation. The photocatalytic efficiency of the samples was estimated by water-splitting $\mathrm{H}_{2}$ production under visible-light irradiation. In addition, the photocatalytic mechanism of GaN:ZnO solid solution under visible-light irradiation was proposed.

\section{Materials and Methods}

\subsection{Materials}

Gallium nitrate $\left(\mathrm{Ga}\left(\mathrm{NO}_{3}\right)_{3} \cdot x \mathrm{H}_{2} \mathrm{O}\right)$ and Trisodium Hexachlororhodate $\left(\mathrm{Na}_{3} \mathrm{RhCl}_{6} \cdot x \mathrm{H}_{2} \mathrm{O}\right)$ were purchased from Aladdin and Alfa Aesar Companies, respectively. Zinc nitrate $\left(\mathrm{Zn}\left(\mathrm{NO}_{3}\right)_{2} \cdot 6 \mathrm{H}_{2} \mathrm{O}\right), \mathrm{N}, \mathrm{N}$-dimethylformamide $(\mathrm{DMF})$, and chromic nitrate $\left(\mathrm{Cr}\left(\mathrm{NO}_{3}\right)_{3} \cdot 9 \mathrm{H}_{2} \mathrm{O}\right)$ were provided by the company of Sinopharm; and polyacrylonitrile (PAN, $\left.\mathrm{Mw}=150,000 \mathrm{~g} \cdot \mathrm{moL}^{-1}\right)$ and methyl alcohol $\left(\mathrm{CH}_{3} \mathrm{OH}\right)$ were obtained from Macklin. All the chemicals were of analytical grade and were used without any purification. Deionized (DI) water was used throughout.

\subsection{Synthesis of $\mathrm{Ga}\left(\mathrm{NO}_{3}\right)_{3}-\mathrm{Zn}\left(\mathrm{NO}_{3}\right)_{3} / \mathrm{PAN}$ Nanofibers and $\mathrm{GaN}: \mathrm{ZnO}$ Solid Solutions}

The $10 \mathrm{wt} \%$ solution of PAN $\left(\mathrm{Mw}=150,000 \mathrm{~g} \cdot \mathrm{moL}^{-1}\right)$ was prepared by dissolving it in $N, N$-dimethylformamide (DMF). An appropriate amount of $\mathrm{Ga}\left(\mathrm{NO}_{3}\right)_{3} \cdot \mathrm{xH}_{2} \mathrm{O}$ and $\mathrm{Zn}\left(\mathrm{NO}_{3}\right)_{2} \cdot 6 \mathrm{H}_{2} \mathrm{O}$ with a mole ratio of $\mathrm{Ga}$ to $\mathrm{Zn}=1: 1$ was mixed into the as-prepared PAN solution with a weight ratio of PAN to salt of 4:1. Then, it was vigorously stirred at an ambient temperature for $5 \mathrm{~h}$ with the purpose of forming a homogeneous and translucent precursor solution. After, the solution was delivered by syringe with a flow rate of $0.6 \mathrm{~mL} \cdot \mathrm{h}^{-1}$ and using a high voltage of $28.5 \mathrm{kV}$, and the distance between the needle tip and the collector was $15 \mathrm{~cm}$. Herein, the obtained $\mathrm{Ga}\left(\mathrm{NO}_{3}\right)_{3}-\mathrm{Zn}\left(\mathrm{NO}_{3}\right)_{3} / \mathrm{PAN}$ nanofiber was preserved in a desiccator at room temperature.

The as-spun composite nanofibers were nitrided at temperatures of 750, 850, and $950{ }^{\circ} \mathrm{C}$ for $3 \mathrm{~h}$ with a heating rate of $5^{\circ} \mathrm{C} \cdot \mathrm{min}^{-1}$ in a flow of $150 \mathrm{sccm} \mathrm{NH}$, respectively, and then the as-nitrided samples were calcined at $400{ }^{\circ} \mathrm{C}$ for $2 \mathrm{~h}$ with a cooling rate of $5{ }^{\circ} \mathrm{C} \cdot \mathrm{min}^{-1}$ and continuously at $500{ }^{\circ} \mathrm{C}$ for $3 \mathrm{~h}$ in the air atmosphere. Three samples of $\mathrm{GaN}: \mathrm{ZnO}$ solid solutions synthesized at different nitriding temperatures were denoted as $\mathrm{S}_{750}, \mathrm{~S}_{850}$, and $\mathrm{S}_{950}$, respectively. 


\subsection{Preparation of $\mathrm{Rh}_{2-y} \mathrm{Cr}_{y} \mathrm{O}_{3}-\mathrm{GaN}: \mathrm{ZnO}$ Photocatalyst}

Briefly, $4 \mathrm{~mL}$ of distilled water containing an appropriate amount of $\mathrm{Na}_{3} \mathrm{RhCl}_{6} \cdot \mathrm{nH}_{2} \mathrm{O}$ (Rh $17.8 \mathrm{wt} \%$ ) and $\mathrm{Cr}\left(\mathrm{NO}_{3}\right)_{3} \cdot 9 \mathrm{H}_{2} \mathrm{O}$ were added into $0.1 \mathrm{~g}$ of $\mathrm{GaN}: \mathrm{ZnO}$ solid solution and the obtained sample was dried at $60^{\circ} \mathrm{C}$ after the suspension was stirred to complete evaporation. The resulting powder was heated at $350^{\circ} \mathrm{C}$ for $1 \mathrm{~h}$ in air atmosphere, and the sample of $\mathrm{Rh}_{2-y} \mathrm{Cr}_{\mathrm{y}} \mathrm{O}_{3}-\mathrm{GaN}: \mathrm{ZnO}$ was obtained, where $\mathrm{Rh}$ and $\mathrm{Cr}$ were loaded at a ratio of $1 \mathrm{wt} \%$ and $1.5 \mathrm{wt} \%$ (metallic content).

\subsection{Characterization}

$\mathrm{X}$-ray diffraction (XRD) was recorded on a Bruker D8 Advance X-ray diffractometer using $\mathrm{Cu}-\mathrm{K} \alpha$ radiation operating at an accelerating voltage and applied current of $40 \mathrm{kV}$ and $40 \mathrm{~mA}$, respectively. UV-visible diffuse reflectance spectra (DRS) were measured using a Varian Cary 500 apparatus equipped with an integrating sphere, using $\mathrm{BaSO}_{4}$ as a reference. Field emission scanning electron microscopy (SEM, JEOL JSM-7500F) was used to characterize the morphology of the as-prepared samples. The (high-resolution) transmission electron microscopy ((HR)TEM, JEOL JEM-2100) images were obtained with accelerating voltages of $200 \mathrm{kV}$. Photoluminescence (PL) measurements were detected on an FLSP920 (EI) fluorescence spectrophotometer. Photocurrent measurements and Mott-Schottky curves were recorded using an electrochemical workstation (Versa STAT3, Princeton Instruments, America). The specific preparation method of the working electrode was as follows: $5 \mathrm{mg}$ of sample were ultrasonically dispersed in $1 \mathrm{~mL}$ of $N, N$-dimethylformamide solution, and then $10 \mu \mathrm{L}$ of the above turbid solution were coated (the coating area was $0.5 \mathrm{~cm} \times 0.5 \mathrm{~cm}$ ) on the FTO conductive glass.

\subsection{Photocatalytic Measurements}

Hydrogen evolution experiments were performed in a glass closed photocatalytic activity evaluation system (LabSolar-IIIAG, Perfectlight). The light source was provided by a $300 \mathrm{~W}$ Xe lamp (PLS-SXE300, Perfectlight) equipped with a filter to block certain light $(\lambda<400 \mathrm{~nm})$. Then, $100 \mathrm{mg}$ of the as-prepared photocatalyst were dispersed in $100 \mathrm{~mL}$ of distilled water containing $10 \mathrm{vol} \%$ methyl alcohol as the sacrificial agent in a Pyrex top-irradiation reaction vessel. Prior to irradiation, the evaluation system was pumped to remove air. Then, the sealed vessel was illuminated by visible light for $6 \mathrm{~h}$ under constant magnetic stirring. The amount of $\mathrm{H}_{2}$ generated from water splitting was monitored by the gas chromatograph (GC-8A, Shimadzu) equipped with a MS- $5 \AA$ column and a TCD-detector. High-purity argon was employed as a carrier gas.

\section{Results and Discussion}

\subsection{Physicochemical Properties of the Obtained Samples}

Figure 1 shows the crystalline structure of the as-prepared samples obtained at different calcination temperatures. Apparently, the samples of $S_{750}, S_{850}$, and $S_{950}$ exhibited diffraction peaks that were basically attributed to GaN:ZnO solid solution with a wurtzite structure [21]. However, in the comparison of $S_{850}$ and $S_{950}, S_{750}$ showed three peaks at $2 \theta$ values of $30.30,35.70$, and $43.39^{\circ}$, which corresponded to (220), (311), and (400) diffraction planes for $\mathrm{ZnGa}_{2} \mathrm{O}_{4}$ (JCPDS card 860415), indicating its incomplete nitridation. Furthermore, the intensity of the peaks corresponding to the $\mathrm{GaN}: \mathrm{ZnO}$ solid solution in $\mathrm{S}_{750}$ were weaker than that of $S_{850}$ and $S_{950}$, which means the higher nitridation temperature induced a higher crystallinity. The peaks around $37^{\circ}$ of the samples exhibited a higher intensity than that of GaN:ZnO solid solution with the general wurtzite structure, which can be attributed to the stacking disorder of the zinc-blende domain $[39,40]$. To determine the energy range of photoexcitation, diffuse reflectance spectra are illustrated in Figure 1b. It shows the UV-visible absorption spectra of GaN:ZnO solid solution subjected to different calcination temperatures. The samples showed obvious absorption in the visible light region while the calcination temperature had a certain influence on the band gap of the samples. $\mathrm{S}_{850}$ displayed an absorption edge at around $450 \mathrm{~nm}$, corresponding to a band 
gap of about $2.76 \mathrm{eV}$. After increasing the calcination temperature, the absorption edge shifted slightly to longer wavelengths because of the increase of the particle size. For $\mathrm{S}_{750}$, the blue shift in the absorption edge was mainly attributed to the presence of $\mathrm{ZnGa}_{2} \mathrm{O}_{4}$.

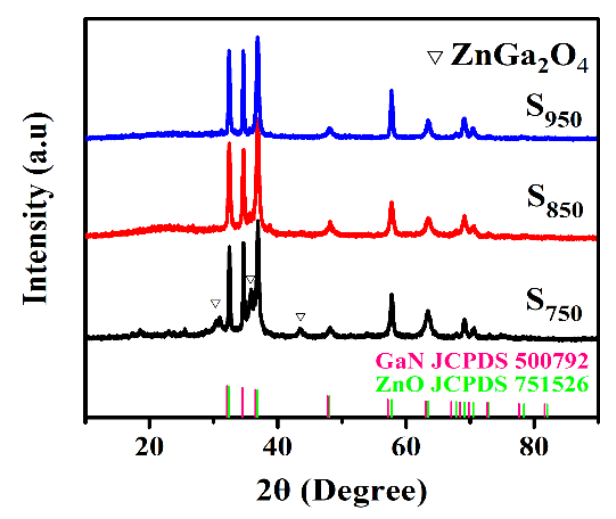

(a)

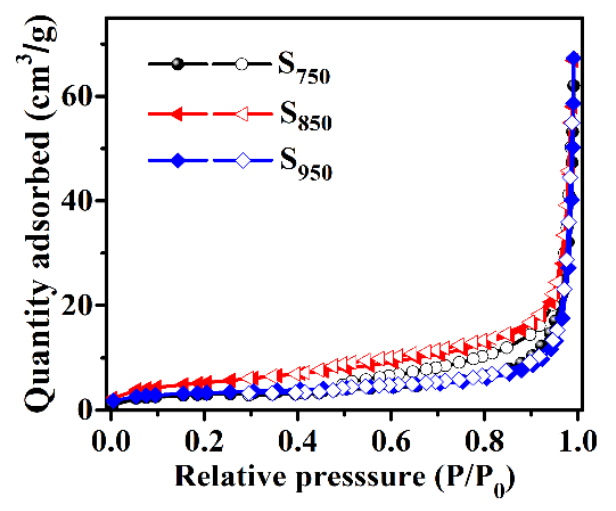

(c)

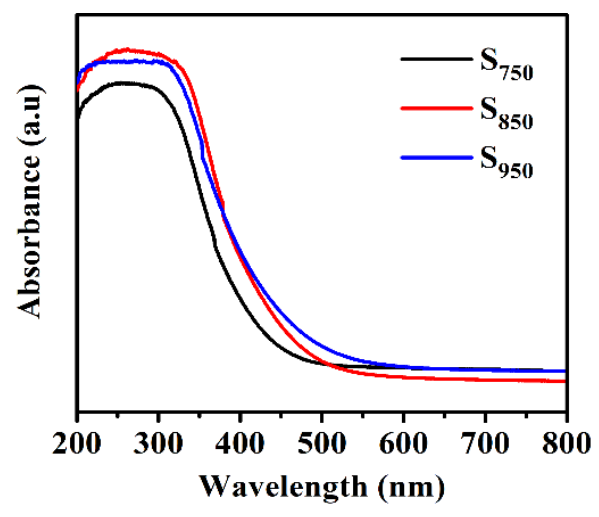

(b)

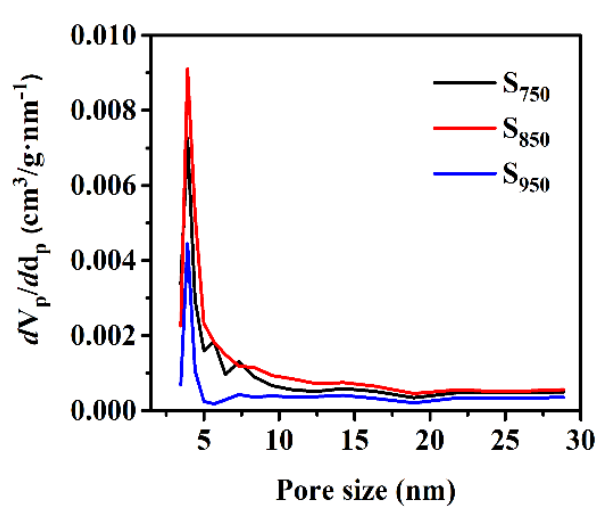

(d)

Figure 1. (a) XRD patterns; (b) UV-visible absorption spectra of the $\mathrm{S}_{750}, \mathrm{~S}_{850}$, and $\mathrm{S}_{950}$ samples; (c) adsorption-desorption isotherms; and (d) pore size distribution of GaN:ZnO solid solution.

The $\mathrm{N}_{2}$ adsorption-desorption isotherms (Figure $\left.1 \mathrm{c}\right)$ show that all three samples $\left(\mathrm{S}_{750}\right.$, $\mathrm{S}_{850}$, and $\mathrm{S}_{950}$ ) displayed type-IV isotherms, which correspond to the mesoporous materials. The BET surface areas of $S_{750}, S_{850}$, and $S_{950}$ were estimated as $18.3,44.8$, and $11.7 \mathrm{~m}^{2} / \mathrm{g}$, respectively. Additionally, the average pore sizes were about 4.0,4.3, and $5.2 \mathrm{~nm}$ for the $S_{750}, S_{850}$, and $S_{950}$ nanorods (Figure $1 d$ ). The main reason for $S_{850}$ having a larger surface area than $S_{750}$ is that the higher temperature is well situated to the pore-forming effect of the release of gases from the thermal polycondensation of PAN. As for $\mathrm{S}_{950}$, the increase of the nitridation temperature led to an enlargement of the nanoparticles that make up the nanorods, resulting in a small surface area. Further, the increased average pore size with the nitridation temperatures can be ascribed to the enlarged particles with an enhanced temperature. In most cases, the higher surface area could provide more active sites in the process of photocatalytic $\mathrm{H}_{2}$ evolution. These results indicate that the change in the specific surface area caused by different nitriding temperatures plays a significant role in the improved photocatalytic performance.

Figure 2a-d show the SEM images of $\mathrm{Ga}\left(\mathrm{NO}_{3}\right)_{3}-\mathrm{Zn}\left(\mathrm{NO}_{3}\right)_{3} / \mathrm{PAN}, \mathrm{S}_{750}, \mathrm{~S}_{850}$, and $\mathrm{S}_{950}$. $\mathrm{Ga}\left(\mathrm{NO}_{3}\right)_{3}-\mathrm{Zn}\left(\mathrm{NO}_{3}\right)_{3} / \mathrm{PAN}$ nanofibers with diameters of around $180 \mathrm{~nm}$, which possess continuous uniform and unblemished smooth structures. Figure $2 b$ shows a broken fiber morphology of $S_{750}$, which can be attributed to the rapid escape of the gas-phase product during the calcination process. In addition, some agglomerates annexed to the fibers' surfaces, which can be assigned to the $\mathrm{ZnGa}_{2} \mathrm{O}_{4}$ residues, and this is in good accordance 
with the XRD analysis. $S_{850}$ exhibited a square rod-like structure consisting of nanoparticles and no agglomerates residues were found on the surfaces of the nanorods (Figure 2c). As for $S_{950}$, the nanoparticles that make up the nanorods grew larger due to to the excessive nitridation temperature as can be clearly seen in Figure 2d. The EDS result (Figure 2e) of $\mathrm{S}_{850}$ evidently confirms the successful synthesis of GaN:ZnO solid solution. The corresponding TEM images of $S_{850}$ further revealed that the nanorods consisted of nanoparticles, as shown in Figure 3a,b. Clear distinct crystal fringes of $d=0.280 \mathrm{~nm}$ and $d=0.246 \mathrm{~nm}$ were observed in the HRTEM images of $S_{850}$, as illustrated in Figure $3 c, d$, which correspond to the (100) and (101) planes of $\mathrm{GaN}$ and $\mathrm{ZnO}$, respectively.

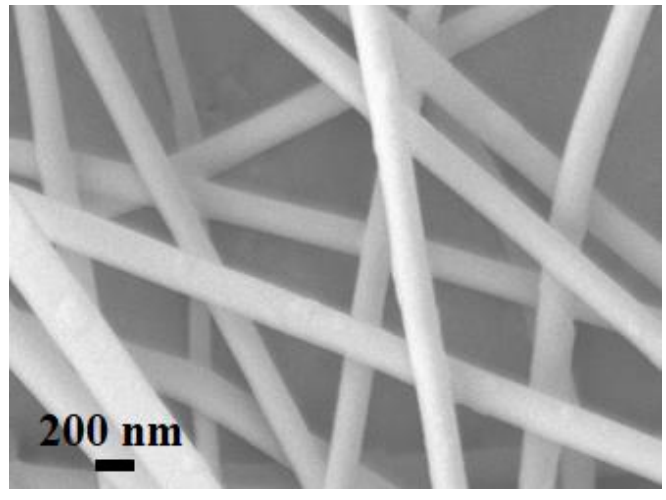

(a)

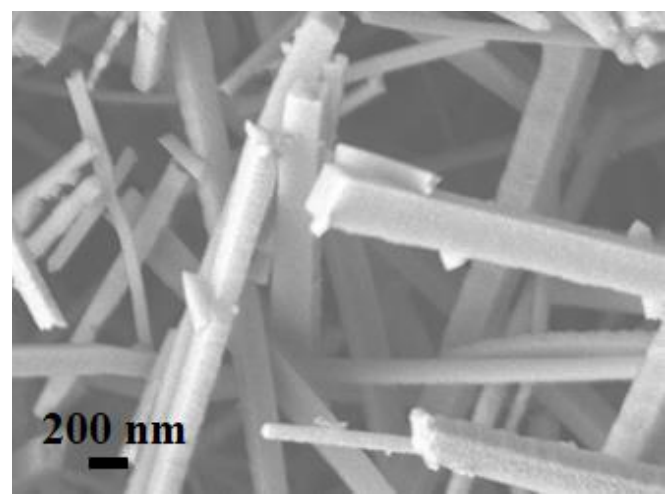

(c)

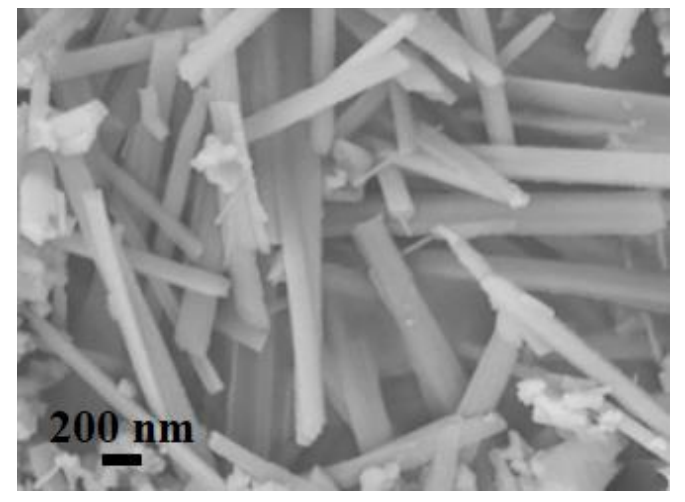

(b)

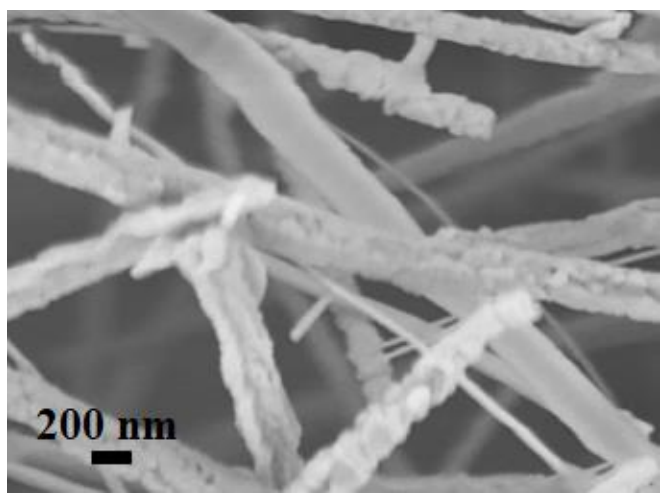

(d)

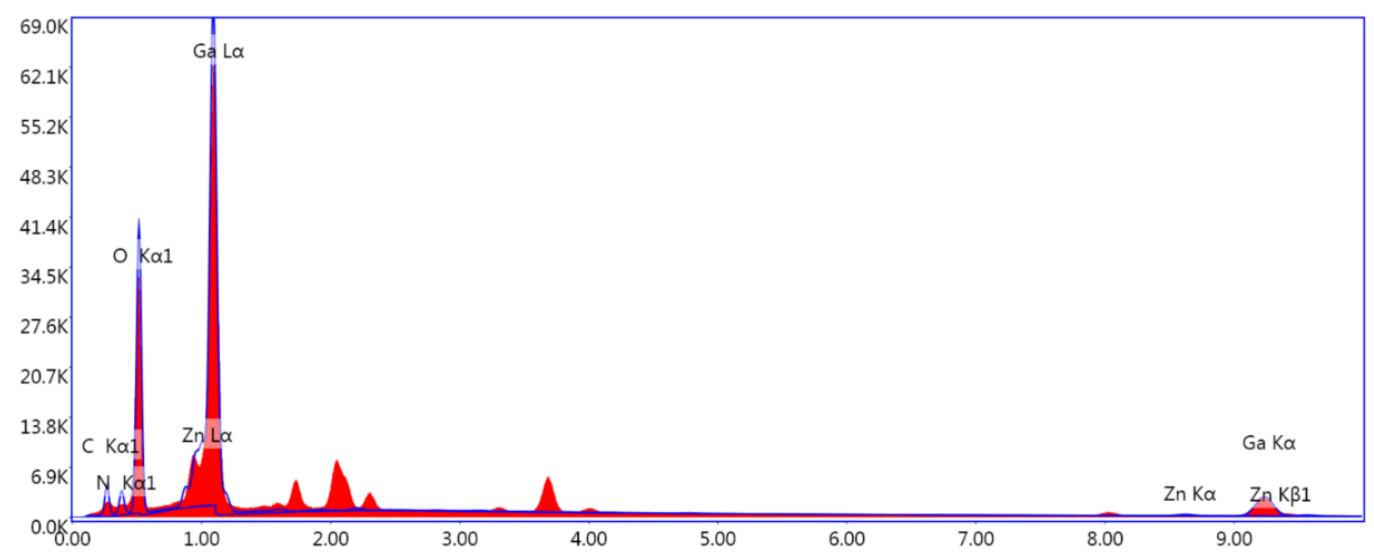

(e)

Figure 2. SEM images of (a) as-spun nanofibers, (b) $S_{750}$, (c) $S_{850}$, and (d) $S_{950}$ and (e) the EDS spectrum of $S_{850}$. 


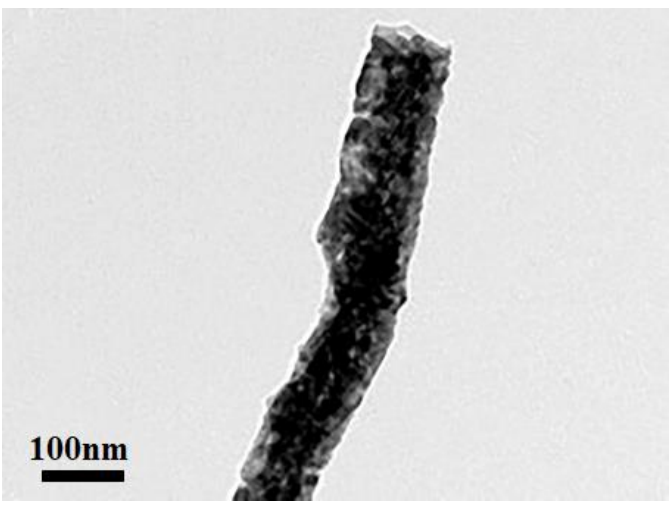

(a)

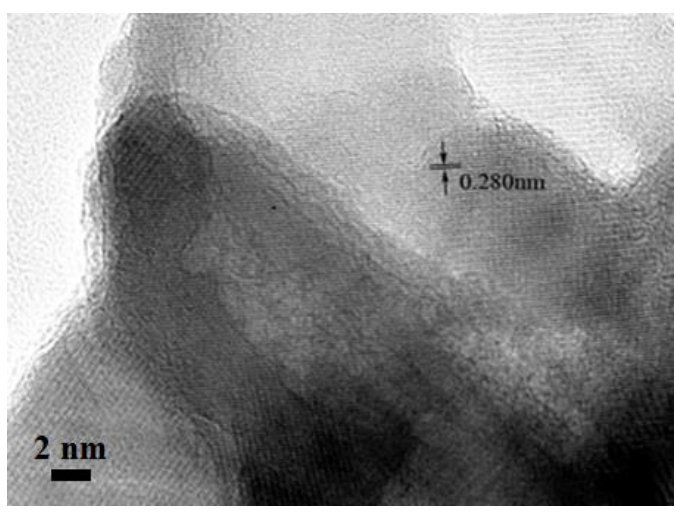

(c)

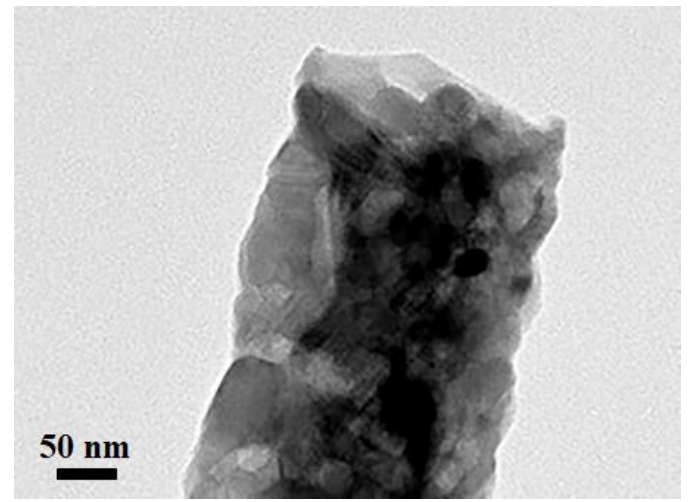

(b)
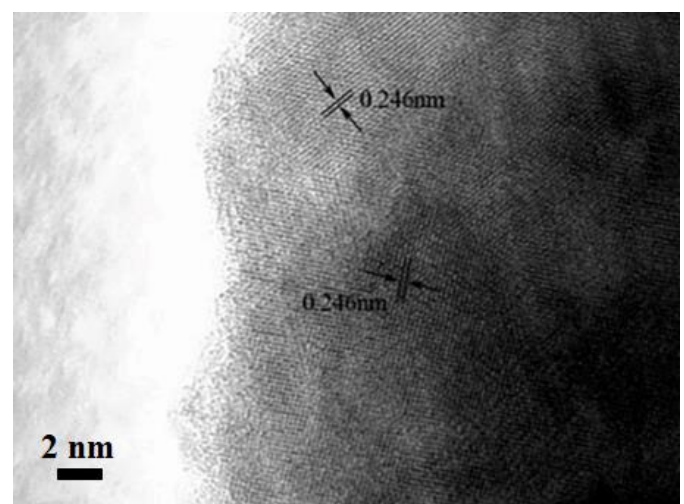

(d)

Figure 3. $(\mathbf{a}, \mathbf{b})$ TEM and $(\mathbf{c}, \mathbf{d})$ HRTEM images of $S_{850}$.

\subsection{Photocatalytic $\mathrm{H}_{2}$ Evolution Performance}

The photocatalytic performance of $\mathrm{GaN}: \mathrm{ZnO}$ solid solution was evaluated by water splitting for $\mathrm{H}_{2}$ production under visible light. Figure 4 a shows the production of $\mathrm{H}_{2}$ of the water splitting reaction on $\mathrm{Rh}_{2-\mathrm{y}} \mathrm{Cr}_{\mathrm{y}} \mathrm{O}_{3}$-loaded $\mathrm{GaN}: \mathrm{ZnO}$ solid solution under xenon lamp irradiation $(\lambda>400 \mathrm{~nm})$. The $\mathrm{H}_{2}$ evolution performance rate in $6 \mathrm{~h}$ is presented in Figure $4 b$, and the average evolution rates of $H_{2}$ for $S_{750}, S_{850}$, and $S_{950}$ were about $47.44,53.44$, and $42.15 \mu \mathrm{moL} \cdot \mathrm{g}^{-1} \cdot \mathrm{h}^{-1}$, respectively. The decreased activity for $\mathrm{S}_{950}$ may be attributed to its nanocrystallite having a larger size, lower BET surface areas, and higher degree of crystallization. As for $\mathrm{S}_{750}$, the lower photocatalytic efficiency can be attributed to the incomplete transformation to $\mathrm{GaN}: \mathrm{ZnO}$ solid solution, associated with the results of XRD and SEM. In addition, the photocatalytic stability of $S_{850}$ was evaluated by the recycling test, which is important for the long-term application of photocatalytic materials. As shown in Figure 4c, over five consecutive cycles, the catalyst exhibited negligible loss of hydrogen evolution activity.

Photoluminescence spectroscopy was employed for the investigation of the charge separation efficiency of the samples in the process of the photocatalytic reaction. Figure $4 \mathrm{~d}$ shows that the emission intensity follows the order of $S_{850}<S_{750}<S_{950}$. The sequence is the opposite of the photocatalytic activity order. Owing to this, the fluorescence was produced by recombination of the holes in the valence band (VB) and the electrons in the conduction band (CB), and the most diminished PL intensity of $S_{850}$ indicates that the recombination of photogenerated charge carriers was maximally retarded [41]. Moreover, the photoelectrochemical measurement further supports the transfer and separation behavior of the photo-induced charge carriers of the samples. As shown in the photocurrent response curves and EIS Nyquist plots in Figure 4e,f, $\mathrm{S}_{850}$ displayed the strongest photocurrent density and the smallest semicircle in comparison with $S_{750}$ and $S_{950}$, suggesting the lowest 
interfacial electron-transfer resistance and the highest photo-induced charge transfer and separation efficiency, which leads to the highest photocatalytic performance.

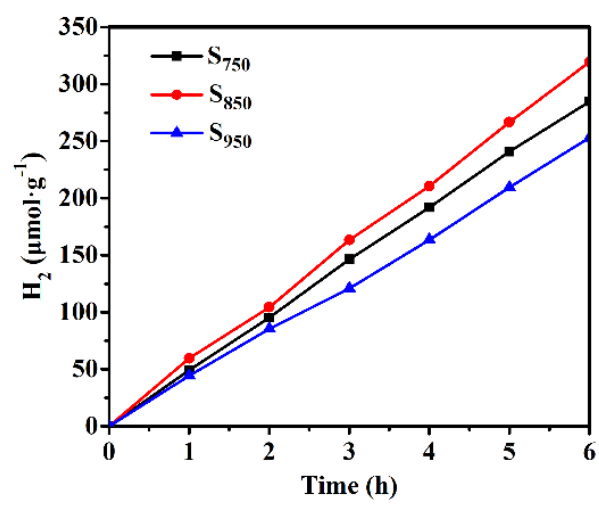

(a)

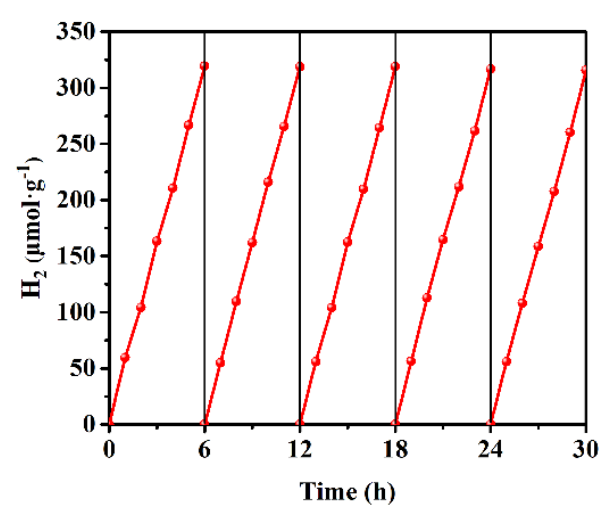

(c)

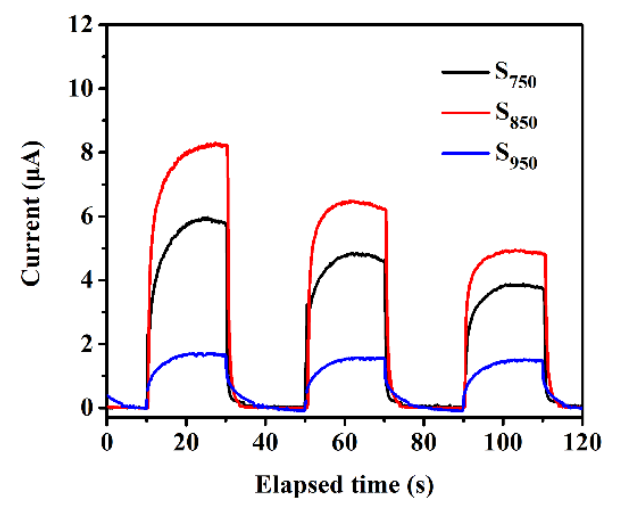

(e)

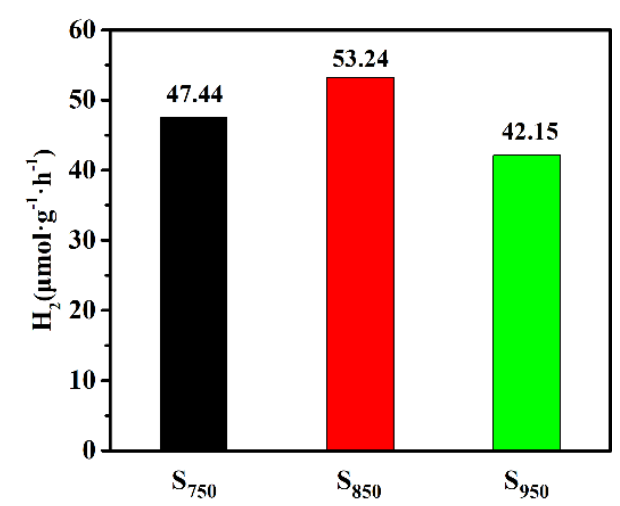

(b)

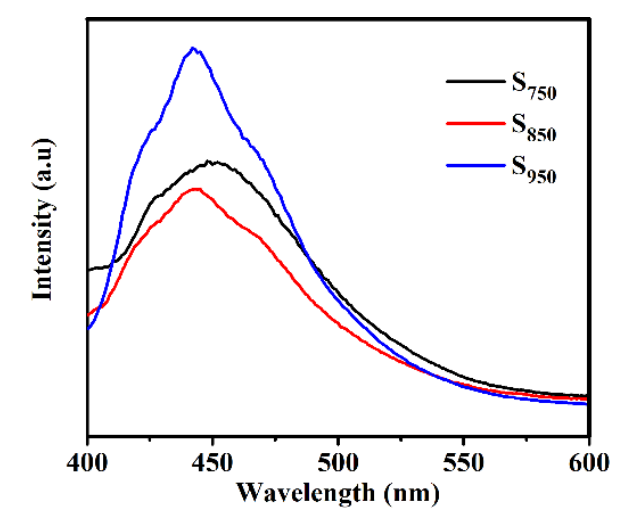

(d)

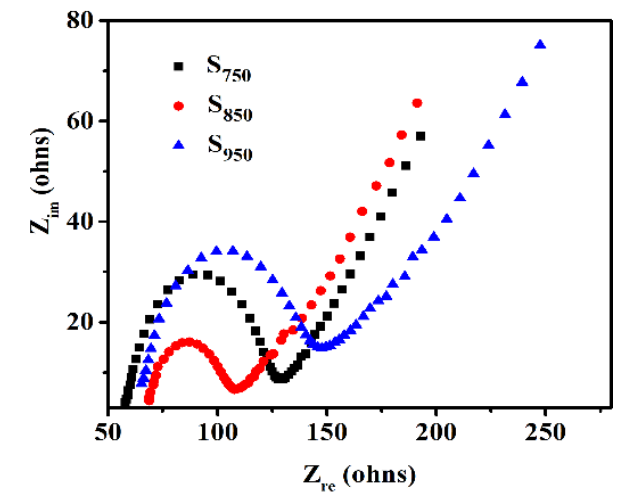

(f)

Figure 4. (a) Photocatalytic $\mathrm{H}_{2}$ evolution and (b) $\mathrm{H}_{2}$ evolution rates of $\mathrm{Rh}_{2-y} \mathrm{Cr}_{\mathrm{y}} \mathrm{O}_{3}$-loaded GaN:ZnO solid solution, (c) cycle stability of $\mathrm{Rh}_{2-y} \mathrm{Cr}_{\mathrm{y}} \mathrm{O}_{3}$-loaded $\mathrm{S}_{850}$, (d) photoluminescence spectra, (e) transient photocurrent, and (f) EIS Nyquist plots of $\mathrm{S}_{750}, \mathrm{~S}_{850}$, and $\mathrm{S}_{950}$ samples.

\subsection{The Mechanism of the Photocatalytic Reaction}

The electronic band structure of the photocatalyst is inevitably linked with the photocatalytic performance. The electronic band structure of $S_{850}$ was investigated by the Mott-Schottky relationship, which can be applied to approximately estimate the potential of the $\mathrm{CB}$ edge of semiconductors. Figure 5 shows the Mott-Schottky plots measured under various $\mathrm{AC}$ frequencies for $\mathrm{S}_{850}$. The $\mathrm{Ag} / \mathrm{AgCl}$ electrode was used as a reference and the measured potentials are thus relative to the $\mathrm{Ag} / \mathrm{AgCl}$ electrode. Apparently, the positive 
slopes of the tangent lines of the Mott-Schottky plots reveal the n-type semiconductor characteristic of $\mathrm{GaN}: \mathrm{ZnO}$ solid solution [42]. The flat band potential obtained from the Mott-Schottky plots shows a frequency dependency. Theoretically, different frequencies have no effect on the flat band potential of the samples. However, it may be inconsistent because of differences in the properties of the samples, such as the degree of dispersion or the thickness of the drop cast films [43]. Using the popular method [43], it can be determined that the flat band potential of $\mathrm{S}_{850}$ is $-1.16 \mathrm{~V}$ vs. an $\mathrm{Ag} / \mathrm{AgCl}$ electrode. For most n-type semiconductors, the bottom of $\mathrm{CB}$ is about $0.10 \sim 0.30 \mathrm{eV}$ higher than the Fermi level and $0.20 \mathrm{eV}$ was selected for $\mathrm{S}_{850}$. Moreover, an $\mathrm{Ag} / \mathrm{AgCl}$ electrode vs. an NHE electrode is $0.22 \mathrm{~V}$. In short, the calculated CB edge potential is $-1.14 \mathrm{~V}$ vs. an NHE electrode. Combined with the band gap value obtained from the UV-visible absorption spectra, the VB position of $S_{850}$ can be calculated as $1.62 \mathrm{~V}$ vs. an NHE electrode. The electronic band structure of $\mathrm{S}_{850}$ is illustrated in Figure 6.

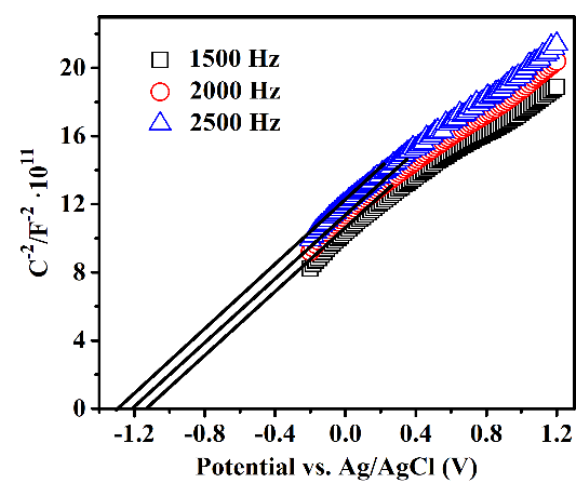

Figure 5. Mott-Schottky plots of $\mathrm{S}_{850}$. Electrolyte: $0.2 \mathrm{M} \mathrm{Na}_{2} \mathrm{SO}_{4}$. The different AC frequencies were used for the measurements: 1500, 2000, and $2500 \mathrm{~Hz}$. Tangent lines of the Mott-Schottky plots were drawn to obtain the flat band potential.

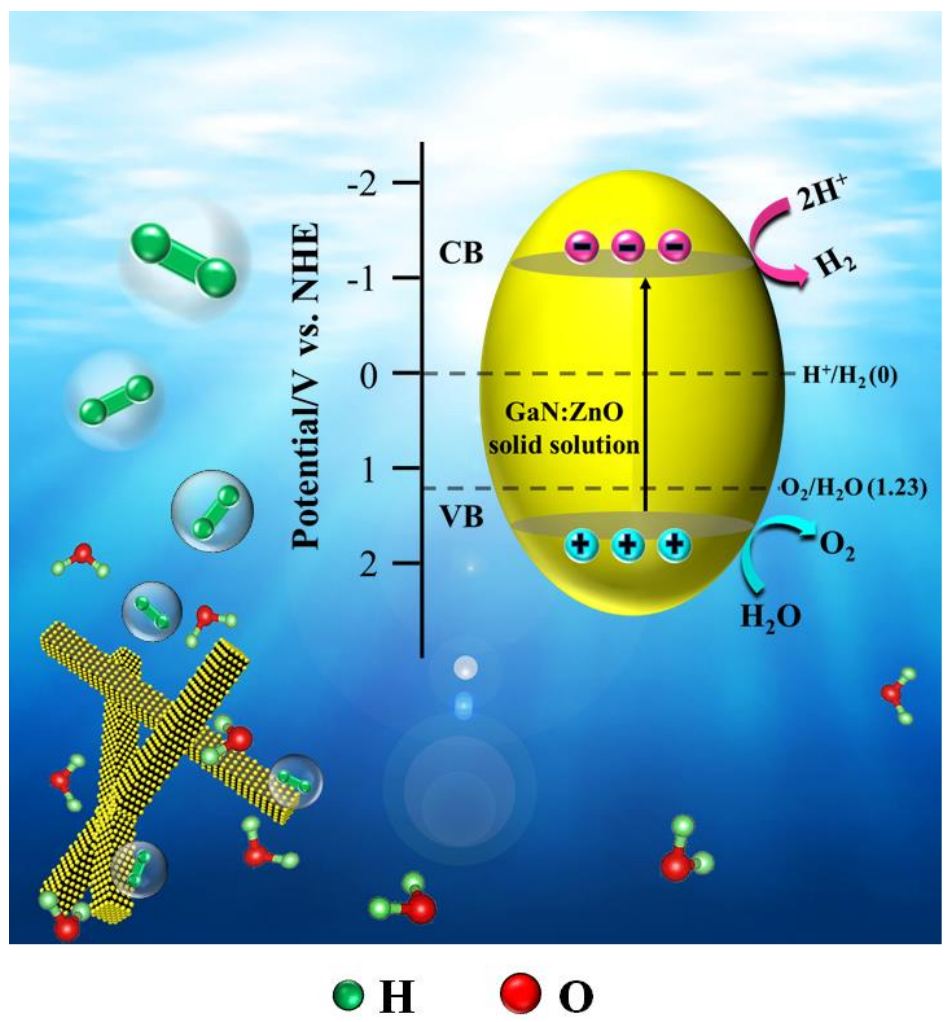

Figure 6. A schematic illustration of the electronic band structure and the photocatalytic $\mathrm{H}_{2}$ generation mechanism of $\mathrm{GaN}: \mathrm{ZnO}$ solid solution. 
In the process of water splitting for $\mathrm{H}_{2}$ production, in order to ensure the progress of the reaction, three conditions must be satisfied: (1) the band gap of the photocatalyst should be greater than the theoretical decomposition voltage of water (1.23 V); and (2) the potentials of photogenerated electrons and holes must satisfy the requirements for reducing water to $\mathrm{H}_{2}$ and oxidizing to $\mathrm{O}_{2}$, respectively. Specifically, the bottom of $\mathrm{CB}$ of the photocatalyst is more negative than the redox potential of $\mathrm{H}^{+} / \mathrm{H}_{2}(0 \mathrm{~V}$ vs. NHE) and the top of VB of the photocatalyst is more positive than the redox potential of $\mathrm{O}_{2} / \mathrm{H}_{2} \mathrm{O}(1.23 \mathrm{~V}$ vs. NHE). (3) The energy provided by light needs to be greater than the band gap of the photocatalyst. As shown in Figure 6, the top of $\mathrm{VB}$ of $\mathrm{S}_{850}$ is positive compared to the redox potential of $\mathrm{O}_{2} / \mathrm{H}_{2} \mathrm{O}$, and the bottom of $\mathrm{CB}$ is negative compared to that of $\mathrm{H}^{+} / \mathrm{H}_{2}$. Therefore, the $\mathrm{GaN}: \mathrm{ZnO}$ solid solution shows efficient performance on photocatalyst water-splitting for $\mathrm{H}_{2}$ production.

\section{Conclusions}

In summary, a new and simple method for the synthesis of $\mathrm{GaN}: \mathrm{ZnO}$ solid solution was proposed using the electrospinning technique. The fabricated GaN:ZnO nanorods nitrided at different temperatures exhibited a mesoporous morphology with disparate specific surface areas. By optimizing the nitridation temperatures, a pure wurtzite phase of $\mathrm{GaN}: \mathrm{ZnO}$ solid solution nanorods was successfully prepared. In comparison with $\mathrm{S}_{750}$ and $S_{950}$, the $S_{850}$ photocatalyst showed outstanding performance regarding the water splitting of $\mathrm{H}_{2}$ evolution under visible-light exposure due to the enhanced specific surface area and photo-induced charge carriers' separation efficiency. The underlying reaction mechanism for the water splitting over $\mathrm{GaN}: \mathrm{ZnO}$ solid solution nanorod photocatalyst was proposed. It is expected to pave a facile and new pathway for the application of electrospinning-based $\mathrm{GaN}: \mathrm{ZnO}$ solid solution in the field of energy conversion.

Author Contributions: J.M. and H.Z. contributed equally to this work. Conceptualization, J.M., H.Z. and H.X.; Data curation, J.M. and H.Z.; Formal analysis, J.M. and H.Z.; Funding acquisition, Q.Q. and H.X.; Investigation, J.M. and H.Z.; Methodology, J.M., H.Z. and H.X.; Supervision, L.X. and H.X.; Visualization, J.M. and H.Z.; Writing—original draft, J.M. and H.Z.; Writing-review \& editing, X.L., Q.Q., Y.L. and H.X. All authors have read and agreed to the published version of the manuscript.

Funding: This work was supported financially by the National Natural Science Foundation of China (NSFC 21875037 and 51502036), National Key Research and Development Program of China (2016YFB0302303 and 2019YFC1908203).

Institutional Review Board Statement: Not applicable.

Informed Consent Statement: Not applicable.

Data Availability Statement: The data presented in this study are available upon request from the corresponding author.

Conflicts of Interest: The authors declare no conflict of interest. The funders had no role in the design of the study; in the collection, analyses, or interpretation of data; in the writing of the manuscript, or in the decision to publish the results.

\section{References}

1. Wei, Z.D.; Liu, J.Y.; Shangguan, W.F. A review on photocatalysis in antibiotic wastewater: Pollutant degradation and hydrogen production. Chin. J. Catal. 2020, 41, 1440-1450. [CrossRef]

2. Fujishima, A.; Honda, K. Electrochemical photolysis of water at a semiconductor electrode. Nature 1972, 238, 37-38. [CrossRef]

3. Qin, Z.Z.; Chen, L.Y.; Ma, R.J.; Tomovska, R.; Luo, X.; Xie, X.L.; Su, T.M.; Ji, H.B. $\mathrm{TiO}_{2} / \mathrm{BiYO}_{3}$ composites for enhanced photocatalytic hydrogen production. J. Alloys Compd. 2020, 836, 155428. [CrossRef]

4. Wang, J.H.; Shen, Y.F.; Liu, S.Q.; Zhang, Y.J. Single 2D mxene precursor-derived $\mathrm{TiO}_{2}$ nanosheets with a uniform decoration of amorphous carbon for enhancing photocatalytic water splitting. Appl. Catal. B-Environ. 2020, 270, 118885. [CrossRef]

5. Fu, B.; Wu, Z.J.; Cao, S.; Guo, K.; Piao, L.Y. Effect of aspect ratios of rutile $\mathrm{TiO}_{2}$ nanorods on overall photocatalytic water splitting performance. Nanoscale 2020, 12, 4895-4902. [CrossRef] [PubMed]

6. Miseki, Y.; Sayama, K. Photocatalytic water splitting employing a $\left[\mathrm{Fe}(\mathrm{CN})_{6}\right]^{3-/ 4-}$ redox mediator under visible light. Catal. Sci. Technol. 2019, 9, 2019-2024. [CrossRef] 
7. Ding, Y.; Wei, D.Q.; He, R.; Yuan, R.S.; Xie, T.F.; Li, Z.H. Rational design of Z-scheme PtS- $\mathrm{ZnIn}_{2} \mathrm{~S}_{4} / \mathrm{WO}_{3}-\mathrm{MnO}_{2}$ for overall photo-catalytic water splitting under visible light. Appl. Catal. B-Environ. 2019, 258, 117948. [CrossRef]

8. He, C.; Han, F.S.; Zhang, J.H.; Zhang, W.X. The $\mathrm{In}_{2} \mathrm{SeS} / \mathrm{g}-\mathrm{C}_{3} \mathrm{~N}_{4}$ heterostructure: A new two-dimensional material for photocatalytic water splitting. J. Mater. Chem. C. 2020, 8, 6923-6930. [CrossRef]

9. Liu, X.C.; Zhang, Q.; Liang, L.W.; Chen, L.T.; Wang, Y.Y.; Tan, X.Q.; Wen, L.; Huang, H.Y. In situ growing of CoO nanoparticles on $\mathrm{g}-\mathrm{C}_{3} \mathrm{~N}_{4}$ composites with highly improved photocatalytic activity for hydrogen evolution. R. Soc. Open Sci. 2019, 6, 190433. [CrossRef] [PubMed]

10. Wang, J.-C.; Hou, Y.X.; Feng, F.-D.; Wang, W.-X.; Shi, W.; Zhang, W.Q.; Li, Y.; Lou, H.H.; Cui, C.-X. A recyclable molten-salt synthesis of $\mathrm{B}$ and $\mathrm{K}$ co-doped $\mathrm{g}-\mathrm{C}_{3} \mathrm{~N}_{4}$ for photocatalysis of overall water vapor splitting. Appl. Surf. Sci. 2021, 537, 148014. [CrossRef]

11. Chen, H.F.; Tan, C.L.; Zhang, K.; Zhao, W.B.; Tian, X.H.; Huang, Y.W. Enhanced photocatalytic performance of ZnO monolayer for water splitting via biaxial strain and external electric field. Appl. Surf. Sci. 2019, 481, 1064-1071. [CrossRef]

12. Zheng, X.Z.; Zhang, Z.; Meng, S.G.; Wang, Y.X.; Li, D.Z. Regulating charge transfer over 3D Au/ZnO hybrid inverse opal toward efficiently photocatalytic degradation of bisphenol A and photoelectrochemical water splitting. Chem. Eng. J. 2020, 393, 124676. [CrossRef]

13. Cai, X.F.; Huang, Y.W.; Hu, J.Z.; Zhu, S.W.; Tian, X.H.; Zhang, K.; Ji, G.J.; Zhang, Y.X.; Fu, Z.D.; Tan, C.L. Tuning photocatalytic performance of multilayer $\mathrm{ZnO}$ for water splitting by biaxial strain composites. Catalysts 2020, 10, 1208. [CrossRef]

14. Suzuki, T.M.; Tanaka, H.; Morikawa, T.; Iwaki, M.; Sato, S.; Saeki, S.; Inoue, M.; Kajino, T.; Motohiro, T. Direct assembly synthesis of metal complex-semiconductor hybrid photocatalysts anchored by phosphonate for highly efficient $\mathrm{CO}_{2}$ reduction. Chem. Commun. 2011, 47, 8673. [CrossRef]

15. Yamada, Y.; Miyahigashi, T.; Kotani, H.; Ohkubo, K.; Fukuzumi, S. Photocatalytic hydrogen evolution under highly basic conditions by using ru nanoparticles and 2-phenyl-4-(1-naphthyl)quinolinium ion. J. Am. Chem. Soc. 2011, 133, 16136-16145. [CrossRef]

16. Tschierlei, S.; Karnahl, M.; Presselt, M.; Dietzek, B.; Guthmuller, J.; González, L.; Schmitt, M.; Rau, S.; Popp, J. Photochemical fate: The first step determines efficiency of $\mathrm{H}_{2}$ formation with a supramolecular photocatalyst. Angew. Chem. Int. Ed. 2010, 49, 3981-3984. [CrossRef]

17. Xu, Q.L.; Zhang, L.Y.; Yu, J.G.; Wageh, S.; Al-Ghamdi, A.A.; Jaroniec, M. Direct Z-scheme photocatalysts: Principles, synthesis, and applications. Mater. Today 2018, 21, 1042-1063. [CrossRef]

18. Fu, J.W.; Yu, J.G.; Jiang, C.J.; Cheng, B. g- $\mathrm{C}_{3} \mathrm{~N}_{4}$-based heterostructured photocatalysts. Adv. Energy Mater. 2018, 8, 1701503. [CrossRef]

19. Li, B.L.; Wang, J.P.; Gao, Z.F.; Shi, H.; Zou, H.L.; Ariga, K.; Leong, D.T. Ratiometric immunoassays built from synergistic photonic absorption of size-diverse semiconducting $\mathrm{MoS}_{2}$ nanostructures. Mater. Horiz. 2019, 6, 563-570. [CrossRef]

20. Abeysinghe, D.; Skrabalak, S.E. Toward shape-controlled metal oxynitride and nitride particles for solar energy applications. ACS Energy Lett. 2018, 3, 1331-1344. [CrossRef]

21. Maeda, K.; Takata, T.; Hara, M.; Saito, N.; Inoue, Y.; Kobayashi, H.; Domen, K. GaN:ZnO solid solution as a photocatalyst for visible-light-driven overall water splitting. J. Am. Chem. Soc. 2005, 127, 8286-8287. [CrossRef] [PubMed]

22. Li, J.; Yang, W.K.; Wu, A.M.; Zhang, X.L.; Xu, T.T.; Liu, B.D. Band-gap tunable 2D hexagonal $(\mathrm{GaN})_{1-\mathrm{x}}(\mathrm{ZnO})_{\mathrm{X}}$ solid-solution nanosheets for photocatalytic water splitting. ACS Appl. Mater. Interfaces 2020, 12, 8583-8591. [CrossRef] [PubMed]

23. Wang, J.P.; Huang, B.B.; Wang, Z.Y.; Wang, P.; Cheng, H.F.; Zheng, Z.K.; Qin, X.Y.; Zhang, X.Y.; Dai, Y.; Whangbo, M.-H. Facile synthesis of $\mathrm{Zn}$-rich $(\mathrm{GaN})_{1-\mathrm{x}}(\mathrm{ZnO})_{\mathrm{x}}$ solid solutions using layered double hydroxides as precursors. J. Mater. Chem. 2011, 21, 4562. [CrossRef]

24. Maeda, K.; Domen, K. Solid solution of $\mathrm{GaN}$ and $\mathrm{ZnO}$ as a stable photocatalyst for overall water splitting under visible light. Chem. Mater. 2010, 22, 612-623. [CrossRef]

25. Asakura, Y.; Nishimura, Y.; Masubuchi, Y.; Yin, S. Utility of $\mathrm{ZnGa}_{2} \mathrm{O}_{4}$ nanoparticles obtained hydrothermally for preparation of GaN:ZnO solid solution nanoparticles and transparent films. Eur. J. Inorg. Chem. 2019, 2019, 1999-2005. [CrossRef]

26. Li, Z.; Qi, Y.; Wang, W.Y.; Li, D.; Li, Z.; Xiao, Y.N.; Han, G.Y.; Shen, J.-R.; Li, C. Blocking backward reaction on hydrogen evolution cocatalyst in a photosystem II hybrid Z-scheme water splitting system. Chin. J. Catal. 2019, 40, 486-494. [CrossRef]

27. Liu, Q.Q.; Huang, J.X.; Tang, H.; Yu, X.H.; Shen, J. Construction $0 \mathrm{D} \mathrm{TiO} 2$ nanoparticles /2D CoP nanosheets heterojunctions for enhanced photocatalytic $\mathrm{H}_{2}$ evolution activity. J. Mater. Sci. Technol. 2020, 56, 196-205. [CrossRef]

28. Mu, L.C.; Zhang, Q.; Tao, X.P.; Zhao, Y.; Wang, S.Y.; Cui, J.Y.; Fan, F.T.; Li, C. Photo-induced self-formation of dual-cocatalysts on semiconductor surface. Chin. J. Catal. 2018, 39, 1730-1735. [CrossRef]

29. Phivilay, S.P.; Roberts, C.A.; Gamalski, A.D.; Stach, E.A.; Zhang, S.; Nguyen, L.; Tang, Y.; Xiong, A.; Puretzky, A.A.; Tao, F.F.; et al. Anatomy of a visible light activated photocatalyst for water splitting. ACS Catal. 2018, 8, 6650-6658. [CrossRef]

30. Chen, L.H.; Chen, R.; Hu, H.F.; Li, G.H. Enhancement of photocatalytic hydrogen production of semiconductor by plasmonic silver nanocubes under visible light. Mater. Lett. 2019, 242, 47-50. [CrossRef]

31. Kosem, N.; Honda, Y.; Watanabe, M.; Takagaki, A.; Tehrani, Z.P.; Haydous, F.; Lippert, T.; Ishihara, T. Photobiocatalytic $\mathrm{H}_{2}$ evolution of GaN:ZnO and [FeFe]-hydrogenase recombinant escherichia coli. Catal. Sci. Technol. 2020, 10, 4042-4052. [CrossRef]

32. Maeda, K.; Teramura, K.; Lu, D.; Takata, T.; Saito, N.; Inoue, Y.; Domen, K. Photocatalyst releasing hydrogen from water. Nature 2006, 440, 295. [CrossRef] 
33. Hagiwara, H.; Kakigi, R.; Takechi, S.; Watanabe, M.; Hinokuma, S.; Ida, S.; Ishihara, T. Effects of preparation condition on the photocatalytic activity of porphyrin-modified GaN:ZnO for water splitting. Surf. Coat. Tech. 2017, 324, 601-606. [CrossRef]

34. Pant, B.; Park, M.; Park, S.-J. Drug delivery applications of core-sheath nanofibers prepared by coaxial electrospinning: A review. Pharmaceutics 2019, 11, 305. [CrossRef]

35. Zhao, K.; Kang, S.-X.; Yang, Y.-Y.; Yu, D.-G. Electrospun functional nanofiber membrane for antibiotic removal in water: Review. Polymers 2021, 13, 226. [CrossRef] [PubMed]

36. Zou, X.X.; Yang, Y.L.; Chen, H.J.; Shi, X.L.; Suo, G.Q.; Ye, X.H.; Zhang, L.; Hou, X.J.; Feng, L.; Chen, Z.-G. Tuning wall thickness of $\mathrm{TiO}_{2}$ microtubes for an enhanced photocatalytic activity with thickness-dependent charge separation efficiency. J. Colloid Interface Sci. 2020, 579, 463-469. [CrossRef] [PubMed]

37. Cheng, J.; Wang, Y.T.; Xing, Y.; Shahid, M.; Pan, W. Surface defects decorated zinc doped gallium oxynitride nanowires with high photocatalytic activity. Appl. Catal. B-Environ. 2017, 209, 53-61. [CrossRef]

38. Li, X.H.; Shao, C.L.; Wang, D.; Zhang, X.; Zhang, P.; Liu, Y.C. Low temperature preparation and characterization of $\left(\mathrm{Ga}_{1-x} \mathrm{Zn}_{x}\right)\left(\mathrm{N}_{1-y} \mathrm{O}_{y}\right)$ alloy nanostructures using electrospun nanofibers as source materials. Ceram. Int. 2014, 40, 3425-3431. [CrossRef]

39. Masubuchi, Y.; Yamaoka, R.; Tohei, T.; Mizoguchi, T.; Ikuhara, Y.; Kikkawa, S. Nanowire of hexagonal gallium oxynitride: Direct observation of its stacking disorder and its long nanowire growth. J. Eur. Ceram. Soc. 2012, 32, 1989-1993. [CrossRef]

40. Miyaake, A.; Masubuchi, Y.; Takeda, T.; Motohashi, T.; Kikkawa, S. Preparation of gallium oxynitride powder and its nanofibers by the nitridation of a gallium oxide precursor doped with nickel or cobalt obtained via the citrate route. Dalton Trans. 2010, 39, 6106. [CrossRef]

41. Luo, Y.J.; Wang, K.C.; Qian, Q.R.; Zheng, W.W.; Xue, H.; Huang, B.Q.; Xiao, L.R.; Chen, Q.H. Fabrication and photocatalytic properties of Gd-doped ZnO nanoparticle-assembled nanorods. Mater. Lett. 2015, 149, 70-73. [CrossRef]

42. Gelderman, K.; Lee, L.; Donne, S.W. Flat-band potential of a semiconductor: Using the mott-schottky equation. J. Chem. Educ. 2007, 84, 685. [CrossRef]

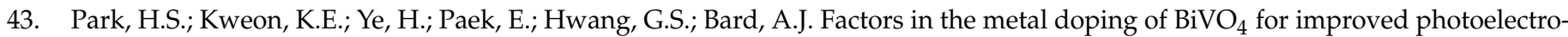
catalytic activity as studied by scanning electrochemical microscopy and first-principles density-functional calculation. J. Phys. Chem. C 2011, 115, 17870-17879. [CrossRef] 